\title{
Competences of polish nurses in the field of prescribing medications: A systematic review
}

\author{
Paulina Kasperska-Dębowska $^{1 *}$, Eliza Oleksy ${ }^{2}$, Anna Wojtczak $^{3}$, Katarzyna Wojtysiak $^{4}$, Jakub Dreliszak $^{5}$, \\ Adriana Wielgus 6 \\ ${ }^{1 * 2,3,4,5,6}$ MD, Faculty of Health Sciences, Collegium Medicum im. Ludwik Rydygier in Bydgoszcz, Nicolaus Copernicus \\ University in Toruń, Poland. \\ Email: *paulaakasperskaa@gmail.com
}

\author{
Keywords \\ Law, Competence, Nurse, Prescribing, Medica- \\ tion, Medical Devices.
}

\section{Article History}

Received on $5^{\text {th }}$ September 2021

Accepted on $30^{\text {th }}$ October 2021

Published on $25^{\text {th }}$ November 2021

\section{Cite this article}

Kasperska-Dębowska, P., Oleksy, E., Wojtczak, A., Wojtysiak, K., Dreliszak, J., \& Wielgus, A. (2021). Competences of polish nurses in the field of prescribing medications: A systematic review. Humanities \& Social Sciences Reviews, 9(6), 1115. https://doi.org/10.18510/hssr.2021.962

Copyright @Author

Publishing License

This work is licensed under a Creative Commons Attribution-Share Alike 4.0 International License (c) (i) (?)

\begin{abstract}
Purpose: The purpose of the following systematic review is to present polish regulations in terms of education, acquiring competencies in the field of prescribing drugs and medical devices.
\end{abstract}

Methodology: The following review can be helpful to conduct comparative meta-analyses. Internet System of Legal Acts, PubMed, Google Scholar research was used to analyze the topic. The selected keywords were used to find information sources: law, competence, nurse, prescribing, medication, medical devices. Articles were selected according to regulations in Poland in terms of education, acquiring competencies in the field of prescribing drugs and medical devices.

Main findings: The increase in nurses' competencies is equivalent to a greater need for knowledge and new knowledge acquired. Nurses take part not only in care and treatment, but also takes independent actions. In such enormous responsibilities, it is crucial to focus on the development of skills. Thus, a competent nurse is interested in continuous professional and personal growth and provides patients with high-quality nursing trustees.

Implications of this study: The results should be considered in health care units, especially Primary Healthcare Units. The paper indicates the regulations in terms of education, acquiring competencies in the field of prescribing drugs which should be revised by personnel and implemented to improve the work of the healthcare unit.

Novelty in this study: There is a lack of systematic reviews of the regulations in Poland in terms of education, acquiring competencies in the field of prescribing drugs and medical devices. The paper is an attempt to assess the topic.

\section{INTRODUCTION}

The work of nurses consists of deliberate and planned activities for the benefit of patient needs. Their professional training aims to maintain and promote health, restore health or reduce the effects of a disease, accompany patients in health, illness, and disability, and shape self-care skills. (The Professions of Nurse and Midwife Act 2011) (Medical Activity Act 2011). Can be moved in the introduction part

According to the Act of Nursing Profession, two groups entitled to prescribe have been distinguished: nurses with a master's degree who have completed a specialist course in this field and have a first-cycle diploma in this field and an appropriate approach. What's more, from the 2017/2018 academic year, students already gain knowledge in this field during their studies. There will be no need for additional education to obtain qualifications to issue prescriptions. The first group is entitled to prescribe medications on their own, except strongly acting, intoxicating, and psychotropic substances and substances for particular nutritional purposes, and some medical devices, including issuing orders or prescriptions for them. These nurses also have the right to write medications for continued treatment. Nurses with a bachelor's degree and a specialist course may only write prescriptions for drugs and preparations under the rules mentioned above but intended only to continue the treatment initiated by the doctor. From January 11, 2019, this group was also able to continue orders for medical devices (The Professions of Nurse and Midwife Act 2011) (Prescriptions Issued by Nurses and Midwives Regulation of Minister of Health 2015).

\section{PURPOSE OF THE RESEARCH}

The purpose of the systematic review is to present the legal regulations in Poland in connection with education, acquiring competencies in the field of prescribing drugs and medical devices by nurses.

\section{METHODOLOGY}

A systematic review can be used to conduct comparative meta-analyses - the Internet System of Legal Acts, PubMed, Google Scholar research was used to analyze the problem. The various keywords were used to find information: law, 
competence, nurse, prescribing, drugs, medical devices. Articles were selected according to regulations in Poland in terms of education, acquiring competencies in the field of prescribing medicines and medical devices.

\section{REVIEW ANALYSIS / DISCUSSION}

\section{Nurse's education and qualifications in Poland}

The professions of nurse and midwife define Polish Act from July 15, 2011, includes:

- Practicing disciplines.

- Obtaining the right to practice a profession.

- Vocational training for a nurse and midwife.

- Postgraduate training for a nurse and midwife.

A nurse receives a professional qualification after graduating from a nursing school. A nursing school is a university that provides education in nursing at the level of first-cycle and second-cycle studies. Teaching in a nursing school lasts at least three years and covers at least 4,600 hours of vocational education, including clinical education at least 1/2, and theoretical education at least $1 / 3$ of the education dimension (The Professions of Nurse and Midwife Act 2011) (The Core Curriculum for Vocational Education Regulation of the Minister of National Education 2012)(The National Accreditation Council of Schools of Nurses and Midwives Regulation of the Minister of Health 2012) (Detailed Requirements for the Education of Nurses and Midwives Regulation of the Minister of Health 2012).

The right to practice the nursing profession is granted to a person: who has a certificate or diploma of graduation from a Polish nursing school or a certificate or diploma obtained in a country other than the European Union Member State, provided that the diploma or certificate has been recognized in Poland as equivalent to the certificate of completion of a nursing school or diploma, and meet the minimum training requirements set out in the provisions of European Union law, who have total legal capacity, whose health condition allows them to perform the profession of a nurse, and shows an impeccable ethical attitude. The career of a nurse may be performed by a person having the right to practice the profession, confirmed or granted by the competent district Council of Nurses and Midwives (The Professions of Nurse and Midwife Act 2011) (The Recognition of University Diplomas Obtained Abroad Regulation of the Minister of Science and Higher Education 2011) (The Adaptation Internship and Skills Test in the Course of Proceedings for Recognition of Qualifications to Perform Regulated Medical Professions Regulation of the Minister of Health 2009).

A nurse is obliged to constantly update his knowledge and professional skills and the right to professional development in various types of postgraduate education (Regulation of the Minister of Health Amending the Regulation on Postgraduate Education for Nurses and Midwives 2020). The following types of postgraduate education are established: specialization training, qualification course, specialist course, training course (The Professions of Nurse and Midwife Act 2011) (Health Care Services Financed from Public Funds Act 2004) (The List of Fields of Nursing and Fields Applicable in Health Care, in Which Specialization and Qualification Courses May Be Conducted, and on Framework Specialization Programs for Nurses and Midwives Regulation of the Minister of Health 2003).

As part of the independent provision of preventive, diagnostic, therapeutic and rehabilitation services, nurses and midwives who have a second degree diploma in nursing or obstetrics or have the title of specialist in the field of nursing and have completed a specialist course "Prescribing drugs" - part I acquire the right to prescribe medication contain active substances, with the exception of drugs contain very potent substances, narcotic drugs and psychotropic substances, and foods for particular nutritional use, as well as prescribing specific medical devices, including issuing orders for them or prescription (Prescriptions Issued by Nurses and Midwives Regulation of Minister of Health 2015) (The Type and Scope of Preventive, Diagnostic, Therapeutic and Rehabilitation Services Provided by a Nurse or a Midwife Independently without a Medical Order Regulation of Minister of Health 2017) (The List of Medicinal Products That May Be Provided Ad Hoc in Connection with the Provided Health Service, and on the List of Medicinal Products Included in Anti-Shock and Life-Saving Kits Regulation of the Minister of Health 2011) (Guaranteed Services in the Field of Primary Health Care Regulation of the Minister of Health 2009).

As part of the implementation of medical orders in the process of diagnosis, treatment, and rehabilitation, nurses and midwives who have a diploma of at least the first degree in nursing or midwifery or have the title of specialist in the field of nursing, acquire the right to issue a prescription for drugs, except medications containing solid substances, narcotic drugs, and psychotropic substances, foodstuffs for particular nutritional uses and medical devices necessary for the continuation of treatment, if they have completed the specialist course "Prescribing medications and prescribing prescriptions" - part II, and also acquire the right to issue orders for medical devices (Prescriptions Issued by Nurses and Midwives Regulation of Minister of Health 2015) (The Scope of Tasks of a Primary Health Care Physician, Nurse and Midwife Regulation of the Minister of Health 2005).

The obligation to complete the specialist course "Prescribing medications and prescribing prescriptions," part I and part II, does not apply to nurses and midwives who, as part of their education in nursing schools or midwives' schools, acquired the knowledge covered by such a course (Article 15a of the Act of July 15, 2011, on the professions of nurse and midwife). Education standards in the fields of nursing or midwifery introducing detailed learning outcomes in the field of prescribing drugs, foodstuffs for particular nutritional uses and medical devices as well as issuing prescriptions 
or orders as part of professional independence or the implementation of medical charges, are applicable from 2016/2017 academic year - in the case of first-cycle studies and from 2017/2018 - in the case of second-cycle studies (Prescriptions Issued by Nurses and Midwives Regulation of Minister of Health 2015).

Nurses and midwives who have completed vocational training in the so-called old education system (medical high school, medical vocational college) may: as part of the independent provision of preventive, diagnostic, therapeutic, rehabilitation services. They can prescribe: drugs that contain specific active substances, exclude very potent substances, intoxicants, psychotropic substances, food for nutritional use when nurse or midwife has the title of specialist in the field of nursing and have completed a specialist course in prescribing medications and prescribing prescriptions - part I. (Prescriptions Issued by Nurses and Midwives Regulation of Minister of Health 2015).

Nurses and midwives can participate in diagnosis, treatment, rehabilitation: prescriptions for medication, exclude medications containing very potent substances, intoxicants, psychotropic substances, food prescriptions for special nutrition issues, medicines for medical devices necessary for treatment continuation if they have the title of specialist in the field of nursing and have completed a specialist course in prescribing drugs and prescribing prescriptions - part II. (Prescriptions Issued by Nurses and Midwives Regulation of Minister of Health 2015).

The first part of the course is about prescribing medications and prescribing and is intended for nurses and midwives with a second-cycle degree in nursing or midwifery and nurses and midwives with the title of specialist in nursing. After completing the first part of the course, the nurse, a midwife, is entitled to provide health services in the following areas:

- Self-prescription of drugs containing certain active substances, except drugs containing very potent substances, narcotic drugs, and psychotropic substances, including prescribing them;

- Self-ordination of special-purpose foodstuffs, including prescription;

- Independent ordination of medical devices, including issuing prescriptions or orders for them;

- Issuing prescriptions as part of the implementation of medical orders in the process of diagnosis, treatment, and rehabilitation for drugs, except for drugs containing powerful substances, narcotic drugs, and psychotropic substances, and for special-purpose foodstuffs necessary for the continuation of treatment;

- Issuing prescriptions or orders as part of the implementation of medical orders in the process of diagnostics, treatment, and rehabilitation for medical devices;

- Independent prescription of OTC (Over-the-counter) drugs (Prescriptions Issued by Nurses and Midwives Regulation of Minister of Health 2015).

Part Two, continuing prescription, is for nurses and midwives with a minimum degree in nursing or midwifery and nurses and midwives with specialist nursing degrees. After completing the second part of the course, the nurse, the midwife is entitled to provide health services in the following areas:

- Issuing prescriptions as part of the implementation of medical orders in the process of diagnosis, treatment, and rehabilitation for drugs, except drugs containing very potent substances, intoxicants, and psychotropic substances necessary for the continuation of treatment;

- Issuing prescriptions as part of the implementation of medical orders in the process of diagnosis, treatment, and rehabilitation for foodstuffs for particular purposes;

- Independent prescription of OTC drugs (Prescriptions Issued by Nurses and Midwives Regulation of Minister of Health 2015).

The education organizer, a specialist course in prescribing drugs and prescriptions for nurses and midwives, should be carried out separately for the first and second parts of the program. After completing the course and passing the exam with a successful result, the training organizer, respectively for the first and second part, issues a certificate of completion of a specialist course to the nurse and midwife, under the model specified in the law. The organizer of the system can be:

- Universities, schools conducting teaching and research activities in the field of medical sciences and medical entities;

- Other entities after being entered into the relevant register of entities providing postgraduate education; the authority keeping the register is the district council of nurses and midwives competent for the place of education and in the case of district chambers of nurses and midwives and commercial law companies established by them, in which they hold shares or stocks, or other entities created by them - the Supreme Council of Nurses and Midwives (Prescriptions Issued by Nurses and Midwives Regulation of Minister of Health 2015).

\section{Prescribing medications by nurses around the world}

Cross-sectional research lasts from December 2014 till July 2015. The study was carried out in 72 randomly selected primary health care centers. The group survey included doctors, nurses, patients, recipients of PCS, residents of the Podkarpackie Voivodeship in Poland. The study counted 2227 participants, included 310 doctors, 539 nurses, and 1378 adult patients registered by medical staff. Polish nurses have new rights to prescribe medications and medical devices 
and repeat prescriptions previously prescribed by doctors. The respondents do not believe that the statutory assignment of new responsibilities for nurses will improve the effectiveness and accessibility of health care services in Poland. (Binkowska-Bury et al., 2016).

Western Europe and Anglo-Saxon countries are already functioning courses for nurses in prescribing drugs (Australia, Canada, Ireland, New Zealand, Sweden, UK, USA). Netherlands and Spain are in the process of being entered for the preceding course. Legal, educational, organizational conditions vary in the above countries, depending on the situations. There are also differences in regulations where prescribing drugs by nurses is only allowed under strict medical supervision (Kroezen et al., 2011) (Bradley \& Nolan, 2007).

The Polish government has defined ten groups of drugs (30 active ingredients) that can be prescribed by nurses, including the following group of drugs: antispasmodics, anticholinergics, antiemetic, anti-infective, antibacterial, local anesthetic, analgesic, anxiolytic, antiparasitic, anti-asthmatic, and anti-migraine. This is a little compared to the Swedish list of 230 drugs prescribed to patients by qualified nurses. In the Netherlands, nurses' prescription of medicines is limited to their area of expertise and competence. In the United States, the nurse has full autonomy in curing narcotic drugs and psychotropic drugs; eligibility varies by state. In developing countries in sub-Saharan Africa, Ethiopia, Malawi, Tanzania, and Zambia, nurses play an essential role in prescribing antiretroviral drugs. In Uganda, due to many cancer and AIDS patients, nurses prescribe antiretroviral drugs and morphine to patients suffering from severe pain. In South Africa, primary care nurses can prescribe medications from the essential medications list as long as three items per prescription. The list of drugs is updated every two years. If the patient needs a different medication is referred to the doctor. Examples of models introduced in other countries are an essential argument in the discussion in Poland about the group of drugs that can be prescribed by a nurse (Binkowska-Bury et al., 2016).

\section{CONCLUSION}

The increase in nursing competencies is synonymous with a greater need for education and acquiring new knowledge. Nurses are not only responsible for nursing and supporting treatment or therapy but also undertaking independent lifesaving actions. To meet such huge responsibility, it is therefore essential to focus on the development of professional skills. In nursing, these skills include the use of knowledge, competencies, and experience by the nurse. Thus, a competent nurse / competent nurse is interested in continuous professional and personal development and providing high-quality nursing care to her patients. The nurse plays an essential role in the nursing and therapeutic team. Like the patient's spokesman on the team forum, a nurse cares about his affairs and well-being. The nurse is an advisor to a person regarding their health and conduct in a given health situation. The nurse consults and offers opinions on people's health choices. A nurse is a complementary or performing caregiver when the patient cannot meet his needs on his own. The nurse is an educator who shapes attitudes, teaches self-care, and motivates to change. It is a guide in activities aimed at a specific goal, which is broadly understood as health. Finally, the nurse is a trustworthy confidant who shows empathy and support.

\section{LIMITATION AND STUDY FORWARD}

Due to the increased burden of work during the pandemic, work regulations regarding medical personnel frequently change. The authors reviewed only publications and regulations available before August 15, 2021. In the future, work can be enlarged with more data content.

\section{CONTRIBUTION}

Paper conception and design: P. Kasperska-Dębowska (16,66\%), E. Oleksy (16,66\%), A. Ziółkowska (16,66\%), K. Wojtysiak (16,66\%), J. Dreliszak (16,66\%), A. Wielgus $(16,66 \%)$

Data collection: P. Kasperska-Dębowska (16,66\%), E. Oleksy (16,66\%), A. Ziółkowska (16,66\%), K. Wojtysiak $(16,66 \%)$, J. Dreliszak $(16,66 \%)$, A. Wielgus $(16,66 \%)$

Manuscript preparation: P. Kasperska-Dębowska (16,66\%), E. Oleksy (16,66\%), A. Ziółkowska (16,66\%), K. Wojtysiak $(16,66 \%)$, J. Dreliszak (16,66\%), A. Wielgus $(16,66 \%)$

All authors reviewed the results and approved the final version of the manuscript.

\section{DISCLOSURE}

The authors report no conflicts of interest in this work.

\section{REFERENCES}

1. Binkowska-Bury, M., Więch, P., Bazaliński, D., Marć, M., Bartosiewicz, A., \& Januszewicz, P. (2016). Nurse prescribing in Poland: Opinions expressed by primary care doctors, nurses, and patients. Medicine (United States), 95(33), e4506. https://doi.org/10.1097/MD.0000000000004506

2. Bradley, E., \& Nolan, P. (2007). Impact of nurse prescribing: A qualitative study. Journal of Advanced Nursing, 59(2), 120-128. https://doi.org/10.1111/j.1365-2648.2007.04295.X

3. Detailed requirements for the education of nurses and midwives Regulation of the Minister of Health 2012 (pl.).

4. Guaranteed services in primary health care Regulation of the Minister of Health 2009 (pl.).

5. Health care services financed from public funds Regulation of the Minister of Health 2004. (pl.). 
6. Kroezen, M., van Dijk, L., Groenewegen, P. P., \& Francke, A. L. (2011). Nurse prescribing of medicines in Western European and Anglo-Saxon countries: A systematic review of the literature. BMC Health Services Research, 11(127), 1-17. https://doi.org/10.1186/1472-6963-11-127

7. Medical activity Regulation of the Minister of Health 2011. (pl.).

8. Prescriptions issued by nurses and midwives Regulation of Minister of Health 2015 (pl.).

9. Regulation of the Minister of Health amending the law on postgraduate education for nurses and midwives 2020 (pl.).

10. The type and scope of preventive, diagnostic, therapeutic, and rehabilitation services provided by a nurse or a midwife independently without a medical order Regulation of Minister of Health 2017 (pl.).

11. The adaptation internship and skills test in proceedings for recognition of qualifications to perform regulated medical professions Regulation of the Minister of Health 2009 (pl.).

12. The core curriculum for vocational education Regulation of the Minister of National Education 2012 (pl.).

13. The list of fields of nursing and fields applicable in health care, in which specialization and qualification courses may be conducted, and on framework specialization programs for nurses and midwives Regulation of the Minister of Health 2003 (pl.).

14. The list of medicinal products that may be provided ad hoc in connection with the provided health service, and on the list of medicinal products included in anti-shock and life-saving kits Regulation of the Minister of Health 2011 (pl.).

15. The National Accreditation Council of Schools of Nurses and Midwives Regulation of the Minister of Health 2012 (pl.).

16. The professions of nurse and midwife Regulation of the Minister of Health 2011 (pl.).

17. The recognition of university diplomas obtained abroad Regulation of the Minister of Science and Higher Education Regulation of the Minister of Health 2011 (pl.).

18. The scope of tasks of a primary health care physician, nurse, and midwife Regulation of the Minister of Health 2005 (pl.).

19. The type and scope of preventive, diagnostic, therapeutic, and rehabilitation services provided by a nurse or a midwife independently without a medical order Regulation of the Minister of Health 2007 (plI.). 